\title{
Synthesis and Characterization of some Disperse Dyes based on Enaminones
}

\author{
Morsy. A. El-Apaserya, Fathy. A. Yassin', Mohamed. H. M. Abd El-Azimb', \\ Mahmoud. E. A. Abdellatif ${ }^{\text {b }}$ \\ ${ }^{a}$ Dyeing, Printing and Textile Auxiliaries Department, Textile Industries Research \\ Division, National Research Centre, 33 El Buhouth St., Cairo, and ${ }^{b}$ Department of \\ Chemistry, Faculty of Science, Zagazig University, Egypt.
}

\begin{abstract}
2-DIMETHYL amino-1-phenyl propenone, 3-Dimethyl amino-1-p-tolyl-propenone and 1-(4-Bromo phenyl)-3-dimethyl amino-propenone 4a-c were gotten in a good yields by reaction of methyl ketones (acetophenone, p-methyl acetophenone, p-bromo acetophenone) with dimethyl formamide dimethyl acetal DMFDMA in para-xylene. Enaminones 4a-c were exposed to coupling process with arylidene diazonium chloride to afford the disperse dyes 7a-f. The substance structures were explained by various diagnostic procedures as well as elemental analysis, Fourier-transform infrared spectroscopy (FT-IR), and nuclear magnetic resonance ${ }^{1} \mathrm{H}-\mathrm{NMR}$ spectra. These disperse dyes delivered of the coupling reaction has affirmed that these colors in the solid state they exists in the anti rather than syn-form.
\end{abstract}

\section{Introduction}

It should be noted that the use of Inaminone has become widespread during the past ten years because of its effective effect in preparing many organic compounds. It understood that enaminones are polydentate reactants that have large function in organic chemistry [1-4]. Enaminones have been utilized in the planning of different naturally dynamic compounds, just as dye intermediates [5]. In past investigations, we have depicted the utility of $\beta$-enaminones as forerunners to polyfunctional organic chemistry [6]. In the exertion portrayed beneath, we have tested the utility of the enaminones synthesis of new azo disperse dyes that could be utilized for dyeing polyester fabrics by various dyeing techniques.

\section{Materials and Methods}

All reactions were trailed by thin layer chromatography (TLC) utilizing Merck aluminum plates. NMR spectra were accounted for by a BRUKER AVANCE 400 spectrometer at $400 \mathrm{MHz}$; substance shifts were recorded in ppm comparative with tetramethylsilane inward standard. Fourier-change infrared (FT-IR) spectra were controlled by a JASCO FT/IR4700 spectrophotometer. Elemental analyses $(\mathrm{C}, \mathrm{H}, \mathrm{N})$ was made utilizing PerkinElmer 2400 analyzer (PerkinElmer, Norwalk, CT, United States). Solvents utilized in this exploration study were gotten from Fluka and Aldrich for both of the synthesis processes and spectroscopic estimations.

General procedures for preparing of enaminones $4 a-c$.

Enaminones $4 \mathrm{a}-\mathrm{c}$ were prepared according to the published procedures [7], a mixtures of methylketones (acetophenone, $p$-methylacetophenone, $\quad p$-bromoacetophenone) 1a-c (0.01 mol) and DMFDMA (1.19 g, 0.01 $\mathrm{mol}$ ) was refluxed for 12-16 h. Completion of the reactions was monitored by TLC. The reaction mixture left to cool to room temperature and then treated with petroleum ether. The solid product, so formed, was collected by filtration and crystalized from a proper solvent to afford compounds 3-Dimethylamino-1-phenylpropenone 4a, 3-Dimethylamino-1-p-tolyl-propenone $4 \mathrm{~b}$ and 1-(4-Bromophenyl)-3-dimethylamino-propenone $4 \mathrm{c}$ as yellow crystals with $60 \%$ yields.

General procedures for preparing of disperse dyes $7 a-f$.

A cold solution of the diazonium salt (10 mmol) (prepared by adding a cold solution of

*E-mail: elapaserym@yahoo.com

DOI: $10.21608 /$ jtcps.2020.22547.1034

C2020National Information and Documentation Centre (NIDOC) 
sodium nitrite $(0.7 \mathrm{~g})$ in water $(5 \mathrm{~mL})$ to a solution of the aniline $(10 \mathrm{mmol})$ in conc. hydrochloric acid $(5 \mathrm{~mL})$ was added to a cold solution of enaminone $4 \mathrm{a}-\mathrm{c}(10 \mathrm{mmol})$ in ethanol $(10 \mathrm{~mL})$ containing sodium sulphate ( $2 \mathrm{~g}$ ). The mixture was stirred at room temperature for $1 \mathrm{~h}$, and the solid precipitate that formed was collected by filtration and crystallized from proper solvents to give yellow crystals.

2-[(4-Chlorophenyl)-hydrazono]-3-oxo-3phenylpropionaldehyde $7 a$

Yield (92\%); m.p. $92{ }^{\circ} \mathrm{C}$

Anal. Calcd For $\mathrm{C}_{15} \mathrm{H}_{11} \mathrm{ClN}_{2} \mathrm{O}_{2}:(286.71), \mathrm{C}$, 62.84; H, 3.87; N, 9.77. Found: C, 63.02, H, 3.53, $\mathrm{N}, 9.50 ; \mathrm{MS} \mathrm{m} / \mathrm{z}(\mathrm{M})^{+}=286.20$; IR: 3063, $(\mathrm{NH})$, 1637 (CO); ${ }^{1} \mathrm{H}$ NMR (DMSO-d6): $\delta=7.42-7.88$ (m, 9H, arom-H), 10.00 (s, 1H, CHO), 14.11 (s, $1 \mathrm{H}, \mathrm{NH})$.

2-[(4-Chlorophenyl)-hydrazono]-3-oxo-3-ptolyl-propionaldehyde $7 b$

Yield (89\%); m.p. $169{ }^{\circ} \mathrm{C}$ Anal. Calcd For $\mathrm{C}_{16} \mathrm{H}_{13} \mathrm{ClN}_{2} \mathrm{O}_{2}:(300.74), \mathrm{C}, 63.90 ; \mathrm{H}, 4.36 ; \mathrm{N}$, 9.31. Found: C, 63.03, H, 4.07, N, 8.70; $\mathrm{MS} \mathrm{m} / \mathrm{z}$ $(\mathrm{M})^{+}=300.18$; IR: 3123, (NH), $1639(\mathrm{CO}) ;{ }^{1} \mathrm{H}$ NMR (DMSO-d6): $\delta=2.40\left(\mathrm{t}, 3 \mathrm{H}, \mathrm{CH}_{3}\right), 7.33-$ 7.84 (m, 8H, arom-H), 9.79 (s, 1H, CHO), 14.10 (s, 1H, NH).

3-(4-Bromophenyl)-2-[(4-chlorophenyl)hydrazono]-3-oxo-propionaldehyde7c

Yield (85\%); m.p. $162{ }^{\circ} \mathrm{C}$ Anal. Calcd For $\mathrm{C}_{15} \mathrm{H}_{10} \mathrm{BrN}_{2} \mathrm{O}_{2}:(365.61), \quad \mathrm{C}, 49.28 ; \mathrm{H}, 2.76 ; \mathrm{N}$, 7.66. Found: C, 50.66, H, 2.76, N, 7.92; MS $\mathrm{m} / \mathrm{z}(\mathrm{M})^{+}=365.06$; IR: 3069, (NH), $1645(\mathrm{CO})$; ${ }^{1} \mathrm{H}$ NMR (DMSO-d6): $\delta=7.44-7.83(\mathrm{~m}, 8 \mathrm{H}$, arom-H), 10.01 (s, 1H, CHO), 14.12 (s, 1H, NH).

2-[(3-Nitrophenyl)-hydrazono]-3-oxo-3-phenylpropionaldehyde $7 d$

Yield (90\%); m.p. $167{ }^{\circ} \mathrm{C}$ Anal. Calcd For $\mathrm{C}_{15} \mathrm{H}_{11} \mathrm{~N}_{3} \mathrm{O}_{4}:(297.27), \mathrm{C}, 60.61 ; \mathrm{H}, 3.73 ; \mathrm{N}, 14.14$. Found: C, 60.04, H, 3.32, N, 14.16; MS m/z (M) ${ }^{+}$ = 297.18; IR: 3177, (NH), 1638 (CO); ${ }^{1} \mathrm{H}$ NMR (DMSO-d6): $\delta=7.54-7.99(\mathrm{~m}, 9 \mathrm{H}$, arom-H), 10.03 (s, 1H, CHO), 13.91 (s, 1H, NH).

2-[(3-Nitrophenyl)-hydrazono]-3-oxo-3-p-tolylpropionaldehyde $7 e$

Yield (83\%); m.p. $153{ }^{\circ} \mathrm{C}$ Anal. Calcd For $\mathrm{C}_{16} \mathrm{H}_{13} \mathrm{~N}_{3} \mathrm{O}_{4}:(311.29), \mathrm{C}, 61.73 ; \mathrm{H}, 4.21 ; \mathrm{N}, 13.50$. Found: C, 61.73, H, 3.45, N, 13.84; MS m/z (M) ${ }^{+}$ J. Text. Color. Polym. Sci. 16, No. 2 (2019)
= 311.17; IR: 3088, (NH), $1637(\mathrm{CO}) ;{ }^{1} \mathrm{H}$ NMR (DMSO-d6): $\delta=2.42\left(\mathrm{t}, 3 \mathrm{H}, \mathrm{CH}_{3}\right), 7.36-7.99$ (m, 8H, arom-H), 10.00 (s, 1H, CHO), 13.97 (s, 1H, $\mathrm{NH})$.

3-(4-Bromophenyl)-2-[(3-nitrophenyl)hydrazono]-3-oxo-propionaldehyde $7 f$

Yield (80\%); m.p. $210{ }^{\circ} \mathrm{C}$ Anal. Calcd For $\mathrm{C}_{15} \mathrm{H}_{10} \mathrm{BrN}_{3} \mathrm{O}_{4}:(376.16), \mathrm{C}, 47.89 ; \mathrm{H}, 2.68 ; \mathrm{N}$, 11.17. Found: C, 47.75, H, 2.50, N, 10.91; MS $\mathrm{m} / \mathrm{z}(\mathrm{M})^{+}=376.10$; IR: 3092, (NH), $1641(\mathrm{CO})$; ${ }^{1} \mathrm{H}$ NMR (DMSO-d6): $\delta=7.66-8.00(\mathrm{~m}, 8 \mathrm{H}$, arom-H), 10.01 (s, 1H, CHO), 13.96 (s, 1H, NH).

\section{$\underline{\text { Result and Discussion }}$}

Scheme 1 shows that enaminones $4 \mathrm{a}-\mathrm{c}$ were synthesized in acceptable yields by condensation reactions of methylketones 1a-c with dimethylformamide dimethyl acetal (DMFDMA) in para-xylene. It is essential that enaminone $7 \mathrm{a}$ was accounted for before to be framed as the trans structure is really delivered a suggestion that is affirmed by the X-ray crystallographic information [8-11]. However it was one report before our published the X-ray data indicated that enaminones were framed the cis-isomer, portrayed by investigation of olefinic proton coupling constants [12].

Conditions for the effective synthesis of enaminones from methylketones and DMFDMA including microwave heating have been accounted for earlier by us and all the more as of late by others [13-17]. We next examined the coupling reaction of enaminone $4 \mathrm{a}-\mathrm{c}$ with arylidene diazonium chloride. This procedure managed new azo disperse dyes $7 \mathrm{a}-\mathrm{f}$, which is practically equivalent to substances that have been recently appeared to exist in the strong state in both syn and anti-forms [11]. As of late we have given X-ray crystallographic data exhibited that the disperse dyes delivered of the coupling reaction has affirmed that these colors in the solid state they exists in the anti rather than syn-form [18].

\section{Conclusion}

A new disperse were successfully incorporated in excellent yields and checked by mass spectroscopy, essential examination, FT-IR, and ${ }^{1} \mathrm{H}-\mathrm{NMR}$ spectroscopy. 


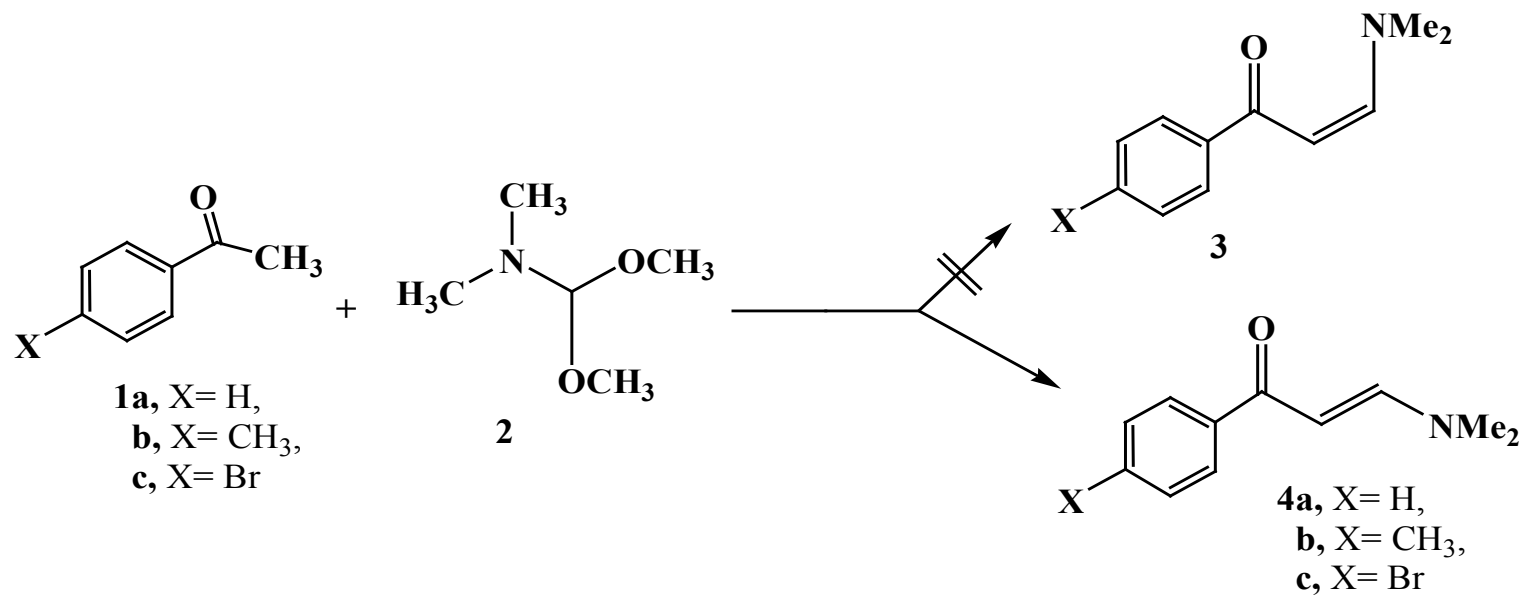$$
\text { c, } \mathrm{X}=\mathrm{Br}
$$

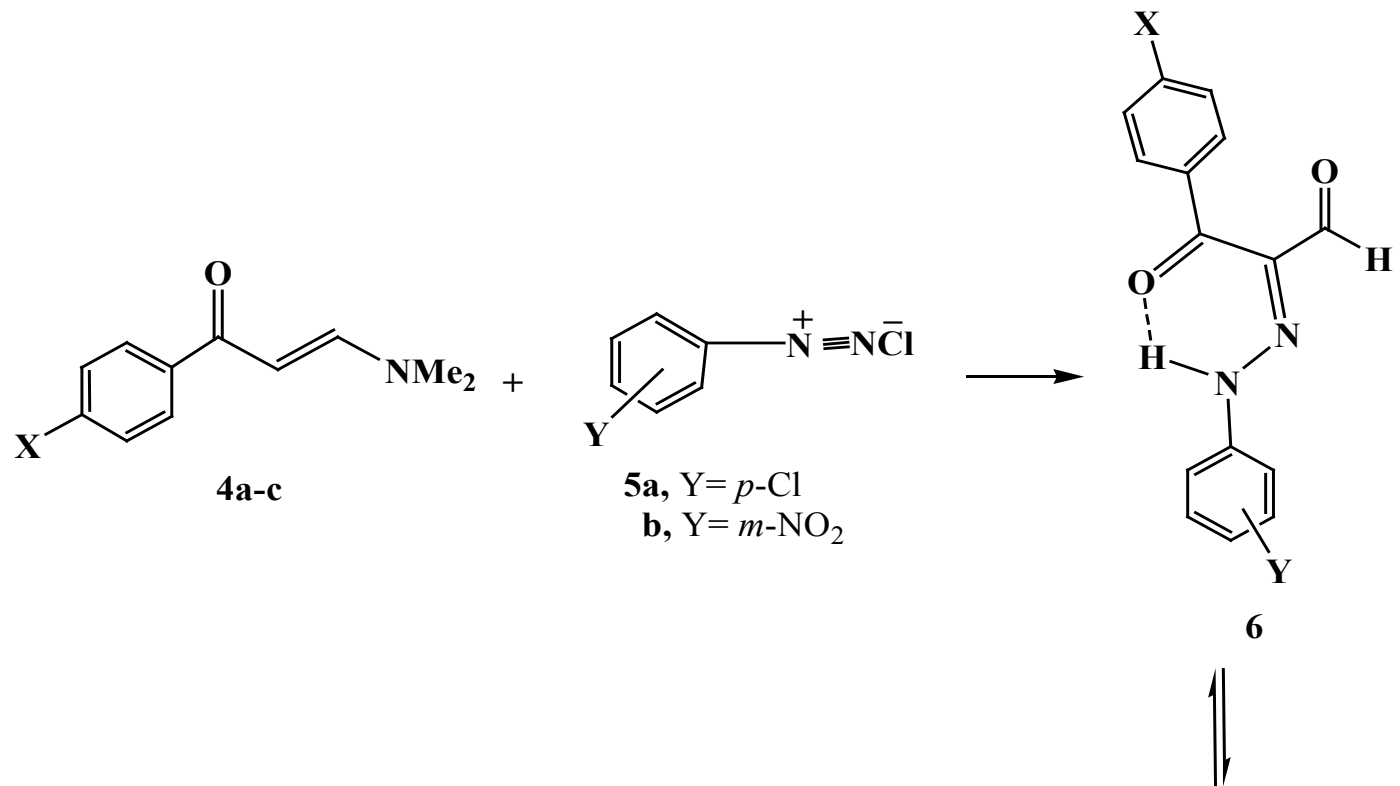<smiles></smiles>

7a, $\mathrm{X}=\mathrm{H}, \quad \mathrm{Y}=p-\mathrm{Cl}$

b, $\mathrm{X}=\mathrm{CH}_{3}, \mathrm{Y}=p-\mathrm{Cl}$

c, $\mathrm{X}=\mathrm{Br}, \quad \mathrm{Y}=p-\mathrm{Cl}$

d, $\mathrm{X}=\mathrm{H}, \quad \mathrm{Y}=m-\mathrm{NO}_{2}$

e, $\mathrm{X}=\mathrm{CH}_{3}, \mathrm{Y}=m-\mathrm{NO}_{2}$

f, $\mathrm{X}=\mathrm{Br}, \quad \mathrm{Y}=m-\mathrm{NO}_{2}$

Scheme 1. Synthesis of azo disperse dyes 7a-f. 


\section{Acknowledgements}

Authors are gratefully thankful for the technical support from both of National Research Centre, Cairo, Egypt. and Zagazig University, Egypt.

\section{References}

1. Alnajjar, A., Abdelkhalik, M. M., Al-Enezi, A., Elnagdi, M. H. Enaminones as building blocks in heterocyclic syntheses: Reinvestigating the product structures of enaminones with malononitrile. A novel route to 6-substituted-3-oxo-2,3dihydropyridazine-4-carboxylic acids. Molecules, 14(1), 68-77 (2009).

2. El-Apasery, M. A.; Hussein, A. M.; El-Adasy, A. A. M.; Saleh, M. O.; Kamel, M. M. Microwave Assisted Synthesis of Some Azo Disperse Dyes with Antibacterial Activities. Part 1, Egypt. J. Chem., 62(5). 1253-1259 (2019).

3. Simunek, P.; Machacek, V. The structure and tautomerism of azo coupled b -Enaminones.Dyes and Pigments, 86(3), 197-205 (2010).

4. Kascheres, C. M. The chemistry of enaminones and small rings: our contribution. J. Braz. Chem. Soc., 14(6), 945-969 (2003).

5. Al-Awadi, N. A., Ibrahim, MR., Abdelhamid, I. A., Elnagdi, M. H. Arylhydrazonals as the aldehyde component in Baylis-Hillman reactions. Tetrahedron, 64(35), 8202-8205 (2008).

6. El-Apasery, M. A., Al-Mousawi, S. M., Mahmoud, H., Elnagdi, M. H. Novel Routes to Biologically Active Enaminones, Dienoic Acid Amides, Arylazonicotinates and Dihydropyridazines under Microwave Irradiation. International Research Journal of Pure \& Applied Chemistry, 1(3), 69-83 (2011).

7. El-Apasery, M.A.;Al-Mousawi, S. M. ; Mahmoud, H.; and Elnagdi, M. H. Studies with Biologically Active Enaminones: An Easy Method for Structural Elucidation of Products Produced from Enaminone Starting Materials through Pathways Employing Microwave Irradiation, International Research Journal of Pure \&Applied Chemistry, 2(1), 77-90 (2012).

8. Al-Mousawi, S. M., El-Apasery, M. A., AlKanderi, N. H. Microwave-assisted organic synthesis: the Gabriel approach as a route to new pyrazolylhydrazonoazoles. ARKIVOC, 16, 268278 (2008).

9. Al-Mousawi, S. M., El-Apasery, M. A., Elnagdi, M. $\mathrm{H}$. Enaminones in heterocyclic synthesis: a novel route to tetrahydropyrimidines, dihydropyridines, triacylbenzenes and naphthofurans under microwave irradiation. Molecules. 15, 58-67 (2010).
10. Al-Mousawi, S. M, El-Apasery, M. A, Elnagdi, M. H. Green methodologies in organic synthesis: Microwave assisted solvent-and catalyst-free synthesis of enaminones and their conversion into 1,3,5-trisubstituted benzenes as well as 3-aroyl6-substituted pyridines. European Journal of Chemistry, 2(2), 168-172 (2011).

11. Al-Saleh, B., El-Apasery, M. A., Abdel-Aziz, R. S., Elnagdi, M. H. Enaminones in heterocyclic synthesis: Synthesis and chemical reactivity of 3-anilino-1-substituted-2-propene-1- one. Journal of Heterocyclic Chemistry, 42(4), 563-566 (2005).

12. Al-Omran, F., El-Khair,A.A. Heterocyclic synthesis via enaminones: novel synthesis of $(1 \mathrm{H})$-pyridin2-one, pyrazolo[1,5-a]pyrimidine and isoxazole derivatives incorporating a $\mathrm{N}$-methylphthalimide and their biological evaluation. Journal of Heterocyclic Chemistry, 42(2), 307-312 (2005).

13. Al-Qalaf, F., Almohammad, K., El-Apasery, M. A., Mahmoud, H. Synthesis of some biologically active monoazo disperse dyes derived from nicotinic acid derivatives under microwave irradiation for dyeing polyester fabrics. Eur. J. Chem. 4, 211-215 (2013).

14. Gorobets, N.Y., Sedash, Y.V., Shishkina, S.V., Shishkin, O.V., Yermolayev, S.A., Desenko, S. M Structure of the intermediate in the synthesis of 6methyl-2-oxo-1,2-dihydropyridine-3-carbonitrile. Arkivoc, 13, 23-30 (2009).

15. El-Adasy, A. A. A. Kamel, M. M.; Saleh, M. O.; Hussein, A. M.; El-Apasery, M. A. Disperse Dyes Based on Pyrazolopyrimidinones I: Their Dyeing Applications and Antimicrobial Activities. Int. $J$. Chem. Tech. Res. 2016, 9, 31-38.

16. Shawali, A. S. Synthesis, reactions and antitumour screening of new enaminones. Journal of Chemical Research, 34(11), 630-634 (2010).

17. Al-Etaibi, A. M., Al-Awadi, N. A., El-Apasery, M. A., Ibrahim, M. R. Synthesis of some novel pyrazolo[1,5-a]pyrimidine derivatives and their application as disperse dyes. Molecules, 16, 5182 $5193(2011)$

18. Al-Awadi, N. A., Elnagdi, M. H., Ibrahim, Y A., Kaul, K., Kumar, A. Efficient synthesis of 3-aroylcinnolines from aryl methyl ketones. Tetrahedron, 57(8), 1609-1614 (2001)

(Received 16/1/2020; accepted 19/1/2020) 


\section{توليف وتوصيف بعض الصبغات المنتشرة المرتكزة على الإينامينونات \\ مرسى الاباصيرى * فتحى ياسين , محمد عبد العظيم ومحمود عبد اللطيف

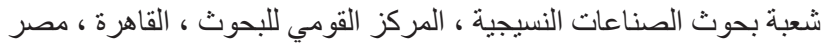

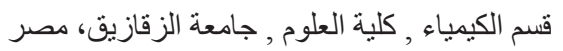

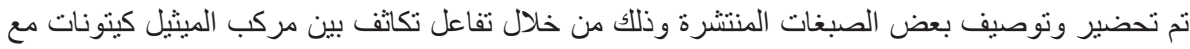

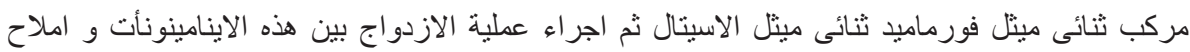

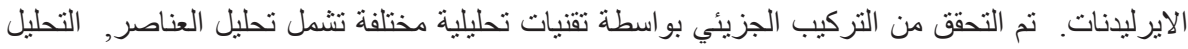

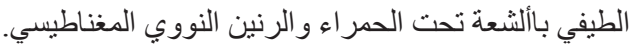

